\title{
Culture Components in the Film Green Book
}

\author{
Yahan Ning \\ Human Science, Macquarie University, Sydney, NSW, 2067, Australia \\ Corresponding E-mail: angela@cas-harbour.org
}

\begin{abstract}
ABATRACT
The story of the film Green book happens in the 1960s America between two different races from separate social classes. These conflicts are all woven into the plot and characters of film. This essay demonstrates the culture components in the film Green book through analyzing the plot of the film and dialogues between different characters. This essay aims to find out influences that the different cultural backgrounds exert on the personality and the behavior of the protagonists. For example, how the protagonists deal with the difficulties and how the cultural differences between the protagonists are indicated to the audience.
\end{abstract}

Keywords: film, culture, race, society environment, social class

\section{INTRODUCTION}

The film Green book is one of the most popular and successful film in 2018. Agar (2018) mentions that the film Green book can owe to the product of terrific performance, sharp and inspiring story, and deft direction[1]. Bonanno (2018) demonstrates that we appreciate things that we haven't seen before, and we all have different tastes[2]. The success of the film is one of the motivation that the author does research on it. The other motivation lies in the strong cultural features that the film present to the audience. According to McCarthy (2018), the title Green book refers to Victor Hugo Green's The Negro Motorist Green Book, which is a tour guide specifically for black people about where they are allowed to go to and stay as well as what kind of service they can expect from different places[5]. Merely the title implicates severe cultural and racial conflicts. In addition, the film is inspired by a true story, in which two men from completely different backgrounds work together by coincidence and become really good friends, eventually. Therefore, the following essay will investigate the culture components in the film Green book through analyzing and interpreting the plot of the film and dialogues between different characters and try to figure out how the external culture exert influences on individuals.

\section{ANALYSIS}

\subsection{The structure of the film}

By looking at the three structures of this film, we can see that by demonstrating and identifying the conflicts in the 1960s America, this film shows a process of changing that happens under the combination and smash between two cultures. Thus the culture components which have been talked about is the clue and thread of the whole film.
Following a Hollywood film three act structure, the first part of the film ended at 23 minutes, which is the point Tony got hired, which could also be regarded as the setup of the film. Up to that point, we all know that how's the two main characters' life like. The second act of the film is the confronting, it demonstrated both Tony and Shirley's thoughts towards the relationship between themselves and the whole society. In the end of this act, Tony started to support Shirley and they both walk out of the racist place where Shirley supposed to performance. Then they went to a neutral and accepting environment like normal friends. In the act three of the film, Tony and Shirley drove back home to celebrate Christmas, up to that point, they all understood each other and the changes have already done. And the film was combined with a large number of set pieces, almost every single scene was equally important, and it all pushing the two characters to a direction of changing their personalities and understanding each other, with a nice confirmation of their friendship at the dinner scenes.

\subsection{Cultural elements}

The culture elements are introduced in a number of aspects including the exposition and preparation of this film and is also combined with a large number of small scenes. The most obvious and the general point is a forever-discussed issue in all the multi-culture societies, race and racism.

First of all, the setting is based on the conflict between the black people and the white people. The time, when the story happens, is set up to the early 1960 s. And the place, where the story happens, is set up to America. This time and place can be traced back to the historical event in American, the Civil Right Movement. The obstacles that Dr. Shirley as a black man is facing will never be confronted or heard of by Tony, the other protagonist who is a white man, no matter in his own personal life nor through the public media.

Secondly, the modern society which we are living in, it is also the setup society in the film, white man are always set up to be the automatic upper class and always gain more attention and respect than black people. For instance, there's 
a scene which Dr. Shirley is being bullied in a bar because he dresses up very decently, and all the white people around mock him by saying "who let him out of his cage? And put that little tie on him too? Who you are dressed out?" This scene demonstrates that the white people suppose that a black man should not dress up nicely and should be in the jail. This thought shows the racial discrimination that the white people have towards the black people: they are all criminals; they are poor and should never dress up properly and never get a chance to have lunch with white people or sit on the same table with them.

Thirdly, the concepts of stereotype, being introduced in the film, about the modern society which the two main character are living in, can be regarded as a setup for the whole environment and the world. The stereotype that black people have towards white people are that white people set up all the rules and give them a really hard time. There is a scene that Dr. Shirley get rejected for using the bathroom during a performance. Dr. Shirley and Tony have to drive back to the hotel to use the toilet there, on the way back, Tony says, "why you sore at me? I don't make the rules down there", and Dr Shirley responses "No? Then who does?" That sentence indicates that in his mind, the stereotype of a white man is that they are always the most powerful people and rule everything and unfriendly towards black people. However, the stereotyped ideas that Shirley has towards Tony is one-sided, while Tony, as a poor, he still feels powerless in a variety of ways. The ruling culture in any societies all effect the citizens in that society in various ways. The most "comfortable" culture or "true ruler" is a portrait of a rich white man.

\subsection{The influence by the cultural background}

The main characters of this film are completely different in all aspects, including skin colors, personalities, jobs, life styles, homes, the way of expression their feelings and the way of dealing with certain problems. They absolutely have nothing in common, which also provide them with an opportunity for them to change.

Tony, from the lower class, is a white man. Although he does not fit the expectations of society towards white people, like rich, knowledgeable, decent as well, he doesn't care about the others' opinion towards him, not even his boss Dr. Shirley. For instance, he forces Dr. Shirley to eat chicken with his hand, what indicates that Tony has a sticky and stubborn thought, which roots in the cultural environment created by the white, that the black people should obey the order of the white people, even against their own will. Moreover, he even feels no guilty about stealing a rock from the shop, because he does not thinks that he has to pay for a stone, while Shirley is under a pressure of the society, that he tends to obey more, so he ask Tony to put back and pay for it. In contrast, Dr. Shirley is a black man with a high dignity and wants himself to stay high all the time. In the beginning of the film, when he is interviewing Tony, he dresses up like a prince, he's room is full of fancy and noble decorations; he refuses to eat chicken with his hand because he thinks it is very unsanitary, and he refuses the suggestion of Tony about pissing in the woods, as he says "animals go into the woods"; when Tony saves him from trouble in the public bath place, he replies terribly to Tony "I need you to stop it with your phony altruism"; and after Kennedy helps him out of the jail, he feels humiliated, and he even says himself is a garbage for doing that. He puts his dignity above everything, above the piano performance which he has to finish, even above essential daily life requirement, such as going to the toilet and eating chicken. All the differences of the two men can be brought back to the point of the society, as the society is ruled by white man, they never give black people enough respect. The white people, even from the lowest class of the society, has privilege over the black people and enjoy more mental freedom and live under less pressure. However, black people like Dr. Shirley, even from the upper class cannot be treated in the same way as poor Tony, they can only give themselves a highly dignity and that is a way for them to against the discrimination from the external world.

However, after the long journey the protagonist accompany each other. Both of them are changed by the other sides. For instance, in 1:42:08, Dr. Shirley stops obey everything and starts to fight over. He says "Either I eat in this room, or I'm not performing tonight". This scene is the greatest change in his attitude. He starts to express his demand instead of sitting there and do nothing. Furthermore, this scene is also marked by the own decision of Tony and leads to the change in him as well, when he starts to understand how difficult it is being a black man. He gives up the prejudice and supports Shirley to skip the performance and drives to a street bar to perform. That indicates the finishing of the inner transformation of the protagonists. At the end, an aftermath of Dr. Shirley and Tony partying at a bar is a wonderful indication of the real friendship of them.

\subsection{Analysis summary}

Above all, in the film, neither Tony nor Dr. Shirley are completely able to fit in the white culture. Tony is white, but he is poor; Dr. Shirley is rich and knowledgeable, but is black. The social marginality appears as the most severe obstacle of the whole film. In addition, the conflicts between these two protagonists attribute to the external culture background and also the internal differences, such as concepts and ideology developed under the cultural impact. they also brought the main character different stories in their lives and also pushed them to change into a direction of getting better in a subtle but sufficient way. The conflicts which the film has demonstrated are not just personal within themselves or even between two of them, but are also part of the large struggle of the society and culture background which is defined by many stereotypes. 


\section{CONCLUSION}

This essay demonstrates the structure of the film, the culture elements regarding the aspects of the whole society, the culture conflicts between different social status and ethnicity, the influences that the culture brings to the personalities and behaviors of the protagonists, and their changes. It all provokes the audience to think about and experience, how people regard different ethnicities and social statues, and how the lives of people from different family backgrounds look like under a "rich-white ruled society".

The concepts in the film which contains race, American social status and the stereotyped ideas that the whole society has towards a certain group of people. Lemire (2018) has discussed that Green Book is kind of old fashioned film-making big studios, but deep down the surface, it contains an emotional, complex issue and it gave us enough a taste of some actual substance[4]. The film demonstrated the ethnicity and status issue in American society in an effective, impressive and direct approach. Moreover, Berardinelli (2018) has put forward that it is inevitable to focus on the sense of humour and the comedy elements in this film, as Green Book used a certain amount of humour to reduce the density and discomfort which could bring up to audience as it is contains a quite sensitive and dark topic of racism[3]. And the clash of two American cultures creates the most interesting drama and attractive focusing point in the whole film.

\section{ACKNOWLEDGMENT}

First and foremost, I would like to show my deepe st gratitude to my teachers and professors in my u niversity, who have provided me with valuable gu idance in every stage of the writing of this thesis. Further, I would like to thank all my friend $s$ and roommates for their encouragement and support. Without all their enlightening instruction and impressive kindness, I could not have comple ted my thesis.

\section{REFERENCES}

[1] C. Agar, Green Book Review: Driving Dr. Shirley, 2018, Retrieved from SCREENRANT. website: https://screenrant.com/green-book-movie-reviews/.

[2] Bonanno, Green Book Movie Review, 2018, Retrieved from DVDizzy. https://www.dvdizzy.com/greenbook-film.html [3] J. Berardinelli, Green Book (United States, 2018), 2018, Retrieved from REELVIEWS. http://www.reelviews.net/reelviews/green-book.

[4] C. Lemire, Green Book, 2018, Retrieved from RogerEbert. https://www.rogerebert.com/reviews/greenbook-2018.

[5] T. McCarthy, 'Green Book': Film Review. TIFF 2018, 2018, Retrieved from The Hollywood Reporter. https://www.hollywoodreporter.com/review/green-bookreview-1142433. 